\title{
Modelos emergentes de gestión de museos e instituciones desde el diálogo con otros agentes culturales
}

Inmaculada Ballesteros | Observatorio de Cultura y Comunicación de la Fundación Alternativas

URL de la contribución <www.iaph.es/revistaph/index.php/revistaph/article/view/4764>

El punto de partida de esta reflexión es el de la crisis evidente de un sistema cultural que, a pesar de autodiagnosticarse de manera continua, no ha sido capaz de afrontar los retos contemporáneos. Los cambios que se han producido en la sociedad en los últimos años no se han visto reflejados en los modelos institucionales decimonónicos que incrementan una fractura intergeneracional e intersectorial soportada desde hace décadas. En cambio, este momento disruptivo que ha traído 2020 puede ser una oportunidad para tomar la iniciativa y atrevernos a pasar a la acción.

Para empezar, tendríamos que replantearnos nuestras políticas culturales desde la ausencia de una ley general de cultura como referencia para la coordinación de la gestión de la cultura en el Estado multinivel. Ante esta evidente falta de proyecto general, deberíamos crear un marco normativo basado en los derechos culturales, pues una de las transformaciones más importantes que

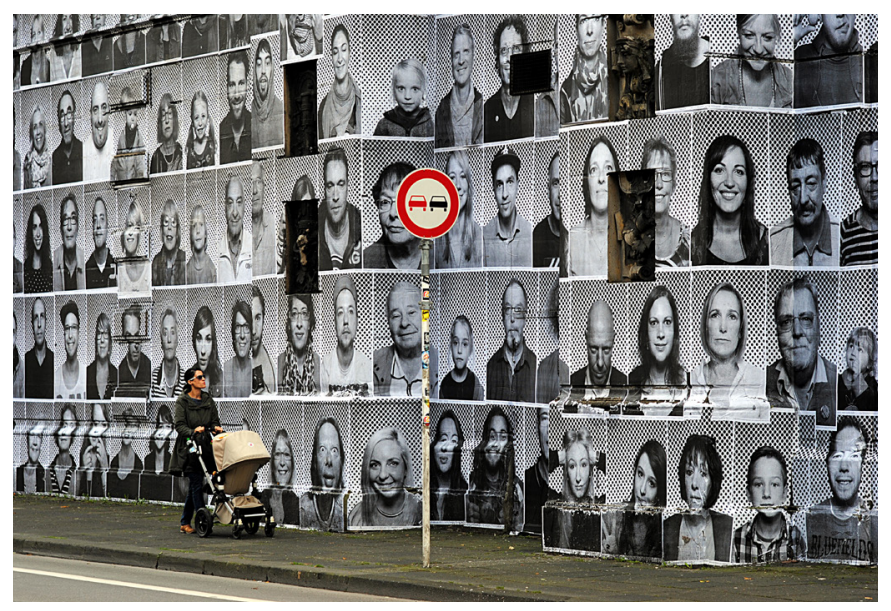

Wuppertal-Elberfeld. Weinkontor (Alemania): Insideout project "different faces different views" del artista frances "JR" | foto Werner Wittersheim ha traído el siglo XXI ha sido la demostración de que la participación social en la vida cultural es elemento clave y base de toda acción. Gestionar esto con modelos de gobernanza obsoletos es prácticamente imposible. Nuestras sociedades mestizas, cosmopolitas, digitales, urbanas y rurales, ecológicas y sostenibles, no pueden ser abarcadas por estructuras rígidas que representan el Estado Nación. Para transformar esta deficiencia debemos pensar en clave de futuro e imaginar el escenario que queremos construir. Sabemos ya que ese futuro va a ser participativo porque el entorno digital lo permite y lo favorece; sabemos también que va a ser híbrido y multidisciplinar porque los enfoques cartesianos ya no son un referente; sabemos que el futuro tiene que ser sostenible y estamos trabajando para conseguirlo. Todo eso necesita un nuevo engranaje.

Partiendo de esta idea, tendremos que buscar fórmulas que habiliten espacios de convivencia entre diferentes disciplinas, donde los saberes se mezclen y se enriquezcan. Será fundamental empezar por la educación y establecer vínculos sólidos con la formación en las escalas formal y no formal. Esta debe ser la base sólida que permita evidenciar el rol social de la cultura y contribuya a la construcción de una identidad basada en valores compartidos que garantice un proyecto sólido de país en el marco europeo de referencia.

El sector de la cultura ha sido siempre el baluarte de la innovación y la creatividad, base del mundo que estamos construyendo. En cambio, la cultura se ha quedado a un lado a la hora de liderar procesos de cambio. Resulta sorprendente que sigamos en esta posición cuando los contenidos culturales lideran el consumo digital y aumentan de manera exponencial las cuentas de resultados de las compañías cotizadas. La tecnolo- 
gía no sería lo mismo sin el audiovisual, la música, el videojuego, el diseño y la publicidad online. Es ahora cuando las instituciones culturales, los museos y centros de creación, deben generar espacios multidisciplinares en los que los contenidos sean accesibles por múltiples canales para llagar a todo tipo de audiencias. Abrir el foco e incorporar públicos diversos que se involucren en el proceso de acción cultural será la manera de adaptar los viejos modelos a la nueva realidad.

Podemos llevar a cabo estos cambios sin perder el valor de la institucionalidad. La pandemia también nos ha servido para demostrar el rol social de lo público. En los peores momentos del confinamiento, en toda Europa se produjo una reacción para dar soporte a las estructuras culturales mientras pasa esta crisis. La cultura se está demostrando necesaria y ha dejado ver de manera clara su valor social. Por eso, es obligación de los poderes públicos garantizar su supervivencia.

En este nuevo modelo que queremos crear será necesario construir un nuevo contrato social en el que las relaciones entre creadores, promotores y público sea más fluida. Es necesario habilitar vías de financiación público-privadas que posibiliten la participación de la sociedad civil en el desarrollo de proyectos culturales. Hay que seguir insistiendo en la necesidad de una Ley de mecenazgo adecuada a las necesidades reales de la cultura como sector social de referencia.

En cuanto a la demostración de que la cultura es un elemento esencial en el desarrollo territorial, tenemos una ocasión sin precedentes de la mano del Pacto Verde Europeo. Es necesario que los gestores culturales públicos y privados aprovechen esta oportunidad para incorporar sus proyectos a las iniciativas europeas. La cultura tiene que estar presente en esta ola transformadora que toma lo digital y la sostenibilidad como referencia. Ese es nuestro verdadero reto y donde deberíamos poner el foco de nuestra metamorfosis. Ahora es el momento y no hay que dejarlo escapar.

\section{BIBLIOGRAFÍA}

- BALlesteros, I. (2019) Cambio climático y desafíos ambientales. Nuevos nichos de empleo para el sector cultural [en línea] Fundación Alternativas, $2019<\mathrm{https}$ :// www.fundacionalternativas.org/cultura-y-comunicacion/ documentos/memorandos-occ/cambio-climatico-y-desafiosambientales-nuevos-nichos-de-empleo-para-el-sectorcultural> [Consulta: 07/09/2020]

- HORIZON 2021-2027, What place for Culture? [en línea] IETM-International network for contemporary performing arts <https://www.ietm.org/en/horizon-europe-2021-2027-whatplace-for-culture> [Consulta: 07/09/2020]

- MARTINELL SEMPERE, A.; BARREIRO CARRIL, B.(2020) Los derechos culturales: Hacia una nueva generación de políticas públicas. Situación y compromisos de España con la comunidad internacional [en línea] Fundación Alternativas, $2020<$ https://www.fundacionalternativas.org/ cultura-y-comunicacion/documentos/documentos-de-trabajo/ los-derechos-culturales-hacia-una-nueva-generacion-depoliticas-publicas-situacion-y-compromisos-de-espana-con-lacomunidad-internacional> [Consulta: 07/09/2020]

- PROGRAMA Europa Creativa 2021-2027 [en línea] Comisión Europea, $2018<$ https://www.creativeeuropeireland. eu/content/resources/budget-may2018-creative-europe_ en.pdf> [Consulta: 07/09/2020]

- SERRANO, M. ${ }^{a}$ M.; FERNÁNDEZ ALLER, C. (2020) El valor del dato en la economía digital [en línea] Fundación Alternativas, $2020<$ https://www.fundacionalternativas.org/ cultura-y-comunicacion/documentos/documentos-de-trabajo/ el-valor-del-dato-en-la-economi\%CC\%81a-digital> [Consulta: 07/09/2020]

- VV. AA. (2020) El Pacto de Reconstrucción Social y Económica [en línea] Fundación Alternativas, $2020<$ https:// www.fundacionalternativas.org/las-publicaciones/informes/ el-pacto-de-reconstruccion-social-y-economica> [Consulta: 07/09/2020] 